were toddlers, Dr Vipulendran and colleagues seem to have used children (aged 0-14?) for the denominator population and have not standardised their results for age. What if Birmingham has more younger Asian than non-Asian children? They have also used data from the 1981 census as the denominator for a numerator sample gathered from two to six years later. What if Asian families have higher fertility rates than non-Asian families? And they have ignored distance from hospital as a factor in admissions. What if more Asian families live nearer the hospital?

Dr Vipulendran and colleagues recognise the contribution of deprivation to child injuries. Dr R Alwash and I interviewed parents of children under 5 years who had attended a hospital accident department in north west London. We also used data from a census as the denominator, with a numerator sample three years later, and we adjusted for distance from hospital. We found no significant ethnic differences in accident rates, but the parents' social class was much more closely associated with variations in accident rate in children under 5 than with the parents' country of birth.

Dr Vipulendran and colleagues related their findings to different methods of cooking in Asian households, but what about the excess of kettle scalds and chemical and other burns in non-Asian children? (The sample is probably too small to be confident about any of these subgroup differences. They recommended an educational service that has been reported from India. In Britain education has been of limited success in preventing accidents to children ${ }^{2}$ and could be divisive if focused on one ethnic group alone. If the underlying causes of such accidents are the material circumstances of families (both the physical environment and cultural expectations) solutions must include socia change.

MARK MCCARTHY

Department of Community Medicin

University College and Middlesex School of Medicine,

London WC1E 6EA

1 Vipulendran V, Lawrence JC, Sunderland R. Ethnic differences in incidence of severe burns and scalds to children in Birmin ham. Br.Med f 1989;298: 1493-4. (3 June.)

2 Alwash R, McCarthy $M$. Accidents in the home among children under 5: ethnic differences or social disadvantage? $\mathrm{Br} \mathrm{Med}$ 1988:296:1450-3.

3 Health Education Authority. Health visiting and prevening accidents to children. London: Health Education Authority, 1987. (Research report No 12.)

4 Black D. Inequalities in health. Report of a research working group. London: Department of Health and Social Security, 1980.

\section{First myocardial infarction in Asian and white men}

SIR, - Dr L O Hughes and colleagues consider that an increased incidence of diabetes may not be relevant to the greater propensity to coronary atheroma in Asians.

We have shown in Leicester that people of Asian origin have a significantly higher relative risk (about 2) of developing non-insulin dependent diabetes than white people and that this persists in all ages over 16 years. ${ }^{2}$ We subsequently performed parallel case referent studies in these two ethnic groups, calculating for each the relative risk of acute myocardial infarction associated with diabetes. The cases were 493 consecutive patients aged 45 or above admitted to the coronary care unit with a proved myocardial infarction (50 Asian, 443 white). The referent population consisted of 17865 people (6949 Asian, 10916 white) aged 45 years or above from the population in which the cases arose. Overall estimates of relative risk were derived using precision based weights, and $95 \%$ confidence intervals were calculated by Miettinen's test based method.

There was a highly significant association between diabetes and acute myocardial infarction in Asians, with an adjusted relative risk of $3 \cdot 3$ ( $95 \%$ confidence interval $1 \cdot 1$ to $8 \cdot 3$ ). In whites the adjusted relative risk was $1.3(1.0$ to 1.7$)$ $(p<0.0005)$. The strength of the association was similar after stratifying for age, indicating lack of interaction between age and diabetes as determinants of risk

Recent research has suggested possible interactions between microalbuminuria or hyper insulinaemia (which may reflect increased insulin resistance) in the association between noninsulin dependent diabetes and ischaemic heart disease. We have shown a greater prevalence of proteinuria in Asian diabetics ${ }^{4}$ and that their first degree relatives have a greater degree of insulin resistance before the onset of clinical diabetes than their white counterparts. ${ }^{4}$ We therefore think that diabetes mellitus is an important risk factor in the development of coronary artery disease in Asians.

A SAMANTA

K L WOODS

A C BURDEN

Leicester Royal Infirmary

Leicester LE1 5WW

1 Hughes LO, Ravel U, Raftery EB. First myocardial infarctions in dsians and white men. Br Med F 1989:298:1345-50. (20 Mav.) Asians and white men. Br.Med $1989 ; 298: 1345-50$. (20 May.) Samanta A, Burden AC, Fent B. Comparative prevalence of
non-insulin-dependent diabetes mellitus in Asian and white Caucasian adults. Diabetes Res Clin Pract 1987;4:1-6.

3 Woods KL, Samanta A, Burden AC. Diabetes mellitus as a risk factor for acute myocardial infarction in Asians and white Caucasians. Br Heurt $\mathcal{f}$ (in pres

4 Samanta A, Burden AC, Feehally J, et al. Diabetic renal disease: differences between Asians and white Caucasians. $\mathrm{Br}$ Med $\mathcal{F}$ $1986 ; 293: 366-7$

Samanta A, O'Rahillys, Nugent Z, et al. First degree relatives of type 2 diabetics. Glucose tolerance and insulin secretion in Asian versus European subjects. Diabetic Med 1986:3:576A.

\section{Plasma cholesterol, coronary heart disease, and cancer}

SIR, - The positive relation between cholesterol and coronary heart disease and the inverse relation between cholesterol and cancer, noted in the Renfrew-Paisley survey, ${ }^{\prime}$ and the negative relation between cholesterol concentration and cancer in China $^{2}$ indicate that a biological variable may have noxious associations with disease in one ethnic group but be less noxious in another.

Our rural African blacks resemble the Chinese: low cholesterol values (mean about $4 \mathrm{mmol} / \mathrm{l}$ ), less than half the incidence of cancer, especially diet related cancers, and coronary heart disease virtually absent. ${ }^{3}$ In contrast, local Indians, with cholesterol values and cancer incidences intermediate between those of the black and white populations, have the highest mortality from coronary heart disease ${ }^{4}$; indeed, wherever Indians migrate their rates tend to become higher than those of the host populations. ' Remarkably, in one report from India the cholesterol concentrations of three quarters of a group of patients with myocardial infarction were less than $4 \mathrm{mmol} / \mathrm{l}^{6}$ Thus, a given cholesterol concentration can be much more pathognomonic of coronary heart disease in one population than in another.

This type of situation also holds to a certain extent for obesity and hypertension. Severe obesity (body mass index $\geqslant 30$ ) is conducive to hypertension, hyperlipidaemia, and hyperglycaemia in white adults but less so in black adults. In studies on obese black women we have found little association with the sequelae mentioned'; actually, over three quarters showed "healthy" obesity, among whom weight reduction is not mandatory. Interestingly, in the United States obesity in blacks is still less promotive of hypertension than it is in whites. "In rural African blacks the prevalence of hypertension is low (a generation ago hypertension was rare); but in big cities its prevalence now exceeds that in whites. ${ }^{10}$ Yet this is consistent with coronary heart disease remaining uncommon.
In other words, both severe obesity and severe hypertension evoke less damage in blacks than would be expected.

There are environmental and metabolic factors which inhibit, and factors which promote or aggravate, disorders and diseases. Yet the identities of many of these factors are unknown. Because of their operation there are numerous puzzling epidemiological occurrences. Thus, in Sydney, Australia, there are threefold differences in colorectal cancer mortality in adjacent districts." Similar inexplicable situations with cancer prevail in Scotland. ${ }^{12}$ Doubtless many unknown factors have contributed to the recent major falls in the incidence of coronary heart disease, stroke, gastric cancer, appendicitis, and dental caries in developed populations. These changes make research in epidemiology so challenging and exciting.

A R P WALKER

B F WALKER

Department of Tropical Pathology,

School of Pathology of the University of the Witwatersrand,

and the South African Institute for Medical Research,

Johannesburg,

South Africa

1 Isles CG, Hole DJ, Gillis CR, Hawthorne VM, Lever AF. Plasma cholesterol, coronary heart disease, and cancer in the Renfrew and Paisley survey. $\mathrm{Br}$ Med $\mathcal{f}$ 1989;298:920-4. (1 April.)

2 Peto R, Boreham J, Chen J, Li J, Campbell TC, Brun T. Plasma holesterol, coronary heart disease, and cancer. $\mathrm{Br}$ Med $\mathcal{Y}$ 1989;298:1249. (6 Miay.)

Walker ARP. Nutrition and public health. South African fournal of Continuing Medical Education 1987;5:15-20.

4 Derry CW, Bourne DE, Sayed AR, et al. Variations in mortality of the coloured, white and Asian population groups in the RSA, 1978-1982. Part IV. Ischaemic heart disease. S Afr Med f 1987;72:698-700.

5 McKeigue PM, Marmot MG. Mortality from coronary heart disease in Asian communities in London. Br Med f 1988;297: 903.

6 Banerjea JC, Mukherjee SK. Some observations on coronary heart disease. Indian Heart f 1970;22:288-99.

7 Walker ARP, Walker BF, Walker AJ, Vorster HH. Low frequency of adverse sequelae of obesity in South African rural black women. In $\mathcal{f}$ Vitam Nutr Res (in press).

8 Knaap TR. A methodological critique of the "ideal weight" concept. FAMA 1983;250:506-10.

Van Itllic TA. Hel 1983,250:506-10. the United States. Ann Intern Med 1985;103:983-8.

10 Seedat YK, Seedat MA, Hackland DBT. Biosocial factors and hypertension in urban and rural Zulu. S Afr Med f 1982;61: $999-1002$

11 Dent $\mathrm{O}$, Goulston K. Geographic distribution and demographic correlates of colorectal cancer mortality in Sydney, New South Wales. Soc Sci Med 1984;19:433-9.

2 Anonymous. Atlas of cancer in Scotland 1975-1980. Incidence and epidemiological perspective. Lyons: IARC Scientific Publications, 1985

\section{Positive end expiratory pressure and oxygen delivery}

SIR, - The conclusion of Drs Mervyn Singer and David Bennett that their results highlight the need to monitor circulatory changes ${ }^{1}$ is a good argument for increasing pulmonary artery catheterisation rather than for "comparatively non-invasive" techniques.

In critically ill patients analysis of mixed venous blood gas tensions to determine oxygen tension and saturation has been stated as the cornerstone of assessment of global oxygen transport, ${ }^{2}$ and adequately mixed blood samples for determining these values can be obtained only from the right ventricular outflow tract or pulmonary artery with a flow directed catheter. Measurements of mixed venous oxygen content and of arterial oxygen content and cardiac output permit calculation of whole body oxygen consumption. All of these values have prognostic and therapeutic importance, ${ }^{3}$ and minimal optimal goals for them have been suggested. ${ }^{+}$Drs Singer and Bennett did not mention absolute values for cardiac output or oxygen delivery so that a comparison with the accepted optimal values for resuscitation cannot be made. 